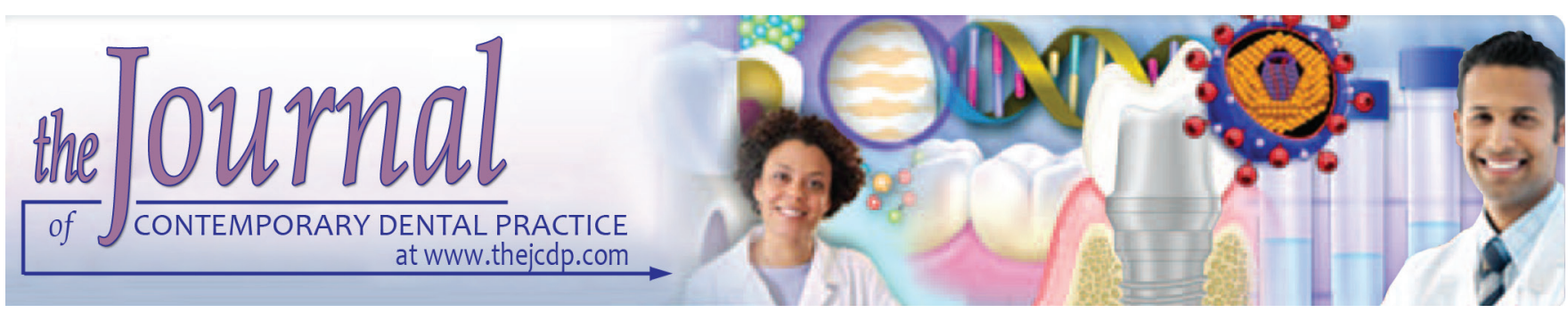

\title{
An in vitro Evaluation of Fracture Resistance of endodontically treated Teeth with Different Restorative Materials
}

${ }^{1}$ Babita Sangwan, ${ }^{2}$ Rahul Rishi, ${ }^{3}$ Mukut Seal, ${ }^{4}$ Kanav Jain, ${ }^{5}$ Pranjali Dutt, ${ }^{6}$ Pratim Talukdar

\section{ABSTRACT}

Aims: The aim of the present study is to compare and assess the fracture resistance of root canal treated teeth with different restorative materials.

Materials and methods: The present in vitro study was carried out on seventy-five freshly extracted, noncarious, single-canal human lower-first premolars with similar anatomic characteristics. Teeth were randomly assigned to five groups with 15 teeth being present in each group. Group I is control group (no alteration done), group II is restored with silver amalgam after endodontic therapy, group III is restored with posterior composite after endodontic therapy, group IV is restored with posterior glass ionomer cement (GIC) after endodontic therapy, and group $V$ is restored with miracle mix after endodontic therapy. Universal testing machine was used to assess the fracture strength. Analysis of variance (ANOVA) test followed by Tukey's post hoc test were used to determine the significant difference between each group. A p-value of $<0.05$ was considered as statistically significant.

\footnotetext{
${ }^{1}$ Department of Conservative Dentistry and Endodontics Panineeya Institute of Dental Sciences and Research Centre Hyderabad, Telangana, India

${ }^{2}$ Department of Conservative Dentistry and Endodontics, Ranchi Jharkhand, India

${ }^{3}$ Department of Conservative Dentistry and Endodontics Regional Dental College, Guwahati, Assam, India

${ }^{4}$ Department of Conservative Dentistry and Endodontics, Jammu Jammu and Kashmir, India

${ }^{5}$ Department of Prosthodontics Crowns and Bridges, Faculty of Dental Science, King George's Medical University, Lucknow Uttar Pradesh, India

${ }^{6}$ Department of Prosthodontics, Daswani Dental College \& Research Center, Kota, Rajasthan, India

Corresponding Author: Babita Sangwan, Senior Lecturer Department of Conservative Dentistry and Endodontics, Panineeya Institute of Dental Sciences and Research Centre, Hyderabad Telangana, India, Phone: +919990116363, e-mail: babitamalhan@ yahoo.com
}

Results: The mean fracture resistance of control group showed highest fracture resistance with a mean Newton of 1083.33 \pm 136.78 . Among the restorative material, the highest fracture resistance was shown by teeth restored by composite $(845.46 \pm 47.36)$, followed by silver amalgam $(845.46 \pm 47.36)$. There was statistically significant difference among all the restorative materials compared with the control group $(p<0.05)$. However, among the teeth restored with silver amalgam and miracle mix, there was no statistical significance $(p>0.05)$.

Conclusion: The present study concludes that composites are found to be having more fracture resistance followed by silver amalgam on endodontically treated premolar teeth.

Clinical significance: Restoring nonvital teeth represents a major challenge for clinicians as they are extensively damaged due to caries and endodontic access preparations. With various restorative materials in the market, it becomes difficult for the clinician to choose the better restorative material for postendodontic restoration.

Keywords: Access cavity, Coronal restoration, Fracture resistance, Root canal treatment.

How to cite this article: Sangwan B, Rishi R, Seal M, Jain K, Dutt $\mathrm{P}$, Talukdar P. An in vitro Evaluation of Fracture Resistance of endodontically treated Teeth with Different Restorative Materials. J Contemp Dent Pract 2016;17(7):549-552.

Source of support: Nil

Conflict of interest: None

\section{INTRODUCTION}

Fracture resistance of an endodontically treated tooth is less when compared with natural tooth as in root canal treated tooth, there will be dehydration and loss of dentin after the procedure, and also some of the vital structures, such as cusps, ridges, and roof of the pulp chamber that provide the support for the natural tooth are distructed. ${ }^{1}$ Hence, restoring the tooth to gain strength is important to protect against fracture. Hence postendodontic 
restoration plays an important role in the success of root canal treated teeth. In addition, restoring root canal treated tooth is necessary to maintain esthetics, function, anatomy of tooth structure, and prevent micro leakage. ${ }^{2}$ Therefore preparation for the access cavity restoration is the final step in root canal therapy.

Restoring nonvital teeth represents a major challenge for clinicians as they are extensively damaged due to caries and endodontic access preparations.

Clinicians suggests full crown coverage after endodontic procedure, however, restoring a root canal treated tooth to its original anatomy may provide good strength and fracture resistance without placement of full coverage restoration could provide potential periodontal and economic benefits to the patients. ${ }^{3}$

Several materials have been suggested as intracoronal restorative materials, such as glass ionomer cement (GIC); composite resins; miracle mix, coremax, and Hi-Dens, which are metal-reinforced GICs. ${ }^{4}$

Dental amalgam is a restoration of choice by many clinicians, but it has a mechanical adhesion to the tooth and also requires proper cavity preparation which may be difficult to consider for a tooth considered for endodontic purpose. Also, studies have reported micro crack propagation under fatigue loading; ${ }^{5}$ hence, it may not provide good fracture resistance of the remaining tooth.

Recently, there are great advancements in adhesive restorative technology, which bonds to the tooth in a conservative and aesthetic manner ${ }^{6}$ resulting in a good bond strength. ${ }^{7}$ Recently, posterior GICs have been claimed to have good strength.

With various restorative materials in the market, it becomes difficult for the clinician to choose the better restorative material for postendodontic restoration. Hence, the present study was designed to compare and assess the fracture resistance of root canal treated tooth restored with silver amalgam, posterior composite, posterior GIC, and miracle mix as coronal restorative materials.

\section{MATERIALS AND METHODS}

Seventy-five noncarious, single-canal human lowerfirst premolars extracted for orthodontic reason having similar morphologic characteristics were selected from the Department of Oral and Maxillofacial Surgery, Panineeya Institute of Dental Sciences and \& Research Centre, Hyderabad. All teeth were stored in saline at room temperature till the procedure was carried out.

\section{Inclusion Criteria}

- Freshly extracted tooth

- Tooth with single canal

- No evidence of root resorption.

\section{Exclusion Criteria}

- Tooth with wasting diseases (attrition, abrasion, erosion)

- Decayed tooth

- Evidence of fracture.

After collecting required number of teeth, the teeth were randomly divided into five experimental groups of 15 teeth each.

Group I: Control group (no alteration done).

Group II: Restored with silver amalgam after endodontic therapy.

Group III: Restored with posterior composite after endodontic therapy.

Group IV: Restored with posterior GIC after endodontic therapy.

Group V: Restored with miracle mix after endodontic therapy.

\section{Procedure}

Similar type of endodontic access cavity was prepared by using F0001 and F0199 burs on all the teeth except control group which was kept without alteration. Biomechanical preparation was done till 50 sized k-file and was obturated with gutta-percha and AH-plus root sealer using cold lateral compaction technique. After obturation, the access cavity was restored by different restorative materials as mentioned above.

Teeth in all the groups were stored at $37^{\circ} \mathrm{C}$ for 3 days. Self-cure acrylic blocks of $4 \times 4 \mathrm{~cm}$ were fabricated onto which the teeth were mounted.

A universal testing machine was used to assess the fracture strength of root canal treated tooth. Load was given vertically down the long axis of the tooth by considering the occlusal inclines of buccal and lingual cusps. The force in Newton needed to fracture each tooth was recorded.

Statistical analysis was done using analysis of variance (ANOVA) to compare different restorative materials followed by Tukey's post hoc for multiple comparisons. A p-value $<0.05$ was considered as statistically significant.

\section{RESULTS}

Table 1 shows the mean fracture resistance of different restorative materials. Control group showed highest fracture resistance with a mean Newton of $1083.33 \pm 136.78$. Among the restorative materials, highest fracture resistance was showed by teeth restored by composite $(845.46 \pm 47.36)$ followed by silver amalgam $(845.46 \pm 47.36)$. Least fracture resistance was exhibited by GIC $(671 \pm 47.36)$ and miracle mix had slightly better fracture resistance than GIC (774 \pm 35.02$)$ but less than composite and silver amalgam. An ANOVA revealed highly statistical difference among the restorative materials and compared with control group (unobturated teeth). 
An in vitro Evaluation of Fracture Resistance of endodontically treated Teeth with Different Restorative Materials

Table 1: Mean fracture resistance of different restorative materials

\begin{tabular}{llllll}
\hline Groups & Mean & $S D$ & $f$-value & $p$-value & Significance \\
\hline I & $1,083.33$ & 136.78 & & & \\
II & 845.46 & 47.36 & & & \\
III & 969.06 & 48.44 & 73.783 & 0.000 & HS \\
IV & 671.33 & 44.98 & & & \\
V & 774.66 & 35.02 & & & \\
\hline p <0.05; HS: Highly significant & & &
\end{tabular}

Table 2: Multiple comparisons using Tukey HSD

\begin{tabular}{|c|c|c|c|c|c|}
\hline \multirow[b]{2}{*}{ Group } & \multirow[b]{2}{*}{$\begin{array}{l}\text { Compared } \\
\text { with }\end{array}$} & \multirow{2}{*}{$\begin{array}{l}\text { Mean } \\
\text { difference } \\
(I-J)\end{array}$} & \multirow[b]{2}{*}{ Sig. } & \multicolumn{2}{|c|}{ 95\% Confidence interval } \\
\hline & & & & $\begin{array}{l}\text { Lower } \\
\text { bound }\end{array}$ & $\begin{array}{l}\text { Upper } \\
\text { bound }\end{array}$ \\
\hline \multirow[t]{4}{*}{ I } & Group II & $237.86^{*}$ & 0.000 & 163.35 & 312.37 \\
\hline & Group III & $114.26^{*}$ & 0.001 & 39.75 & 188.77 \\
\hline & Group IV & $412.00^{*}$ & 0.000 & 337.49 & 486.50 \\
\hline & Group V & $308.66^{*}$ & 0.000 & 234.15 & 383.17 \\
\hline \multirow[t]{3}{*}{ II } & Group III & $123.60^{*}$ & 0.000 & 198.10 & 49.09 \\
\hline & Group IV & $174.13^{*}$ & 0.000 & 99.62 & 248.64 \\
\hline & Group V & 70.80 & 0.070 & 3.70 & 145.30 \\
\hline \multirow[t]{2}{*}{ III } & Group IV & $297.73^{*}$ & 0.000 & 223.22 & 372.24 \\
\hline & Group V & $194.40^{*}$ & 0.000 & 119.89 & 268.90 \\
\hline IV & Group V & $103.33^{*}$ & 0.002 & 177.84 & 28.82 \\
\hline
\end{tabular}

*Significant; $p<0.05$

Table 2 shows multiple comparisons among the restorative materials. There was statistically significant difference among all the restorative materials compared with the control group $(p<0.05)$. However, among the teeth restored with silver amalgam and miracle mix, there was no statistical significance ( $p>0.05)$.

Graph 1 shows mean fracture resistance exhibited by different restorative materials and control group.

\section{DISCUSSION}

We have considered extracted mandibular premolars for the study, but there can be variations which cannot be

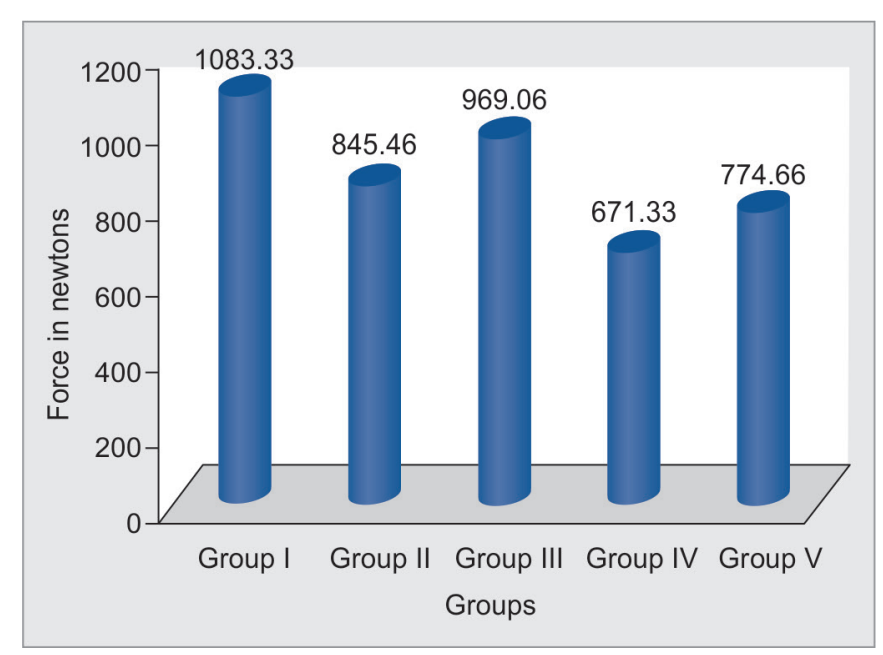

Graph 1: Mean fracture resistance exhibited by different restorative materials and control group controlled between the teeth, hence we have standardized the procedure by considering patients in the same age group going for orthodontic extraction, randomly distributing the teeth to different groups, and making a uniform access cavity preparation mesiodistally and buccolingually as much as possible.

An endodontically treated tooth can be expected to survive in the oral cavity for long duration based on the final restoration that we provide; hence tooth restoration is the final and vital step to determine the success of endodontic treatment. There is evidence that endodontically treated teeth have reduced levels of proprioception which could impair normal protective reflexes that ultimately leads to fracture. ${ }^{8}$

Ability of root canal treated tooth to withstand forces in in vivo condition is different when compared to in vitro as in oral cavity force applied to the tooth may depend upon the position of adjacent teeth, extent of tooth structure remaining, opposite occlusal contacts, periodontal status of the tooth, and many other factors, so more in vivo studies are required before considering the restoration of choice after root canal treatment. Tooth with extensive caries will provide least fracture resistance. Reduction of crown structure during root canal treatment is the reason for weakening of tooth structure. ${ }^{5}$ So preserving tooth structure is a vital step.

Many studies ${ }^{9-11}$ have been done with an intention to know the ideal restorative material for a root canal treated tooth as these teeth are having less fracture resistance because of endodontic access and cavity preparation procedures.

In our study we have included the most commonly used restorative materials that are usually given preference by practicing dentists for core buildup after endodontic treatment, hence we considered composite, silver amalgam, GIC, and miracle mix. We considered maxillary premolars as they are the most prone teeth for fracture. ${ }^{12,13}$

Intact teeth were having highest fracture resistance, which clearly indicates that structural integrity of tooth is of paramount importance for fracture resistance. This was an expected result as cusp separation rarely occurs because of presence of pulp chambers roof and marginal ridges.

In our study fracture resistance exhibited by composite restoration was less when compared to that of normal intact tooth, but more when compared to all other restorative materials used. The results are similar to studies done by Ashika Riswana and Kumari ${ }^{10}$ and Reddy et al. ${ }^{11}$ Also, many studies have shown that composites are having better bonding to tooth structure by micromechanical bonding ${ }^{14,15}$ and exhibit higher mechanical and physical properties compared to various core buildup materials. ${ }^{16}$ 
Most of the time, prognosis of root canal treated tooth depends not only on the endodontic procedure, but also on the restorative material used for the postendodontic restoration. Choosing the best restorative material according to functional needs and considering remaining tooth structure are key factors for success. Based on these points, different materials have been proposed of which we found composite restoration as having more fracture resistance followed by silver amalgam. The main difference for fracture resistance among GIC and composite may be due to physical and mechanical properties and among composites and miracle mix is incorporation of metallic fillers.

In the present study, miracle mix exhibited more fracture resistance compared to GIC, which is in contrast to the study by Reddy et al. ${ }^{11}$ The reason could be that incorporation of metallic fillers may provide additional advantage over conventional GIC. Also, miracle mix has an added advantage of fluoride ion release. $^{17}$

The limitations of this study are considering procedure in in vitro condition, which may not replicate the oral conditions; also, single-rooted tooth was considered. Hence, fracture resistance offered by restorative material for multirooted tooth can be difficult to conclude. Thus, studies under clinical conditions should be considered further to interpret the result of this in vitro study.

\section{CONCLUSION}

From the result of present study, composites are found to be having more fracture resistance followed by silver amalgam on endodontically treated premolar teeth. However, the results of in vitro studies are difficult to interpret in the clinical setting as endodontically filled tooth is influenced by factors like occlusal contact of opposite tooth, tooth position in the arch, extent of caries involvement, strength of cuspal remain. Hence, long-term in vivo studies are required with similar cavity design and different restorative material.

\section{REFERENCES}

1. Belli S, Erdemir A, Yildirm C. Reinforcement effect of polyethylene fibre in root filled teeth: comparison of two restoration techniques. Int Endod J 2006 Feb;39(2):136-142.
2. Daneshkazemi AR. Resistance of bonded composite restoration to fracture of endodontically treated teeth. J Contemp Dent Pract 2004 Aug;5(3):51-58.

3. Steele A, Johnson BR. In vitro fracture strength of endodontically treated premolars. J Endod 1999 Jan;25(1):6-8.

4. Ranga B, Chole DG, Shashank K. Resistance to fracture of endodontically treated premolars restored with glass ionomer cement or acid etch composite resin: an in vitro study. J Int Clin Dent Res Organ 2010;2(3):106-112.

5. Sores PV, Santos-Filho PC, Gomide HA, Araujo CA, Martins LR, Soares CJ. Influence of restorative technique on the biomechanical behavior of endodontically treated maxillary premolars. Part II: strain measurement and stress distribution. J Prosthet Dent 2008 Feb;99(2):114-122.

6. Belli S, Erdemir A, Ozcopur M, Eskitascioglu G. The effect of fibre insertion on fracture resistance of root filled molar teeth with MOD preparation restored with composite. Int Endod J 2005 Feb;38(2):73-80.

7. Sagsun B, Cobankara FK, Orucoglu H. Effect of a new restoration technique on fracture resistance of endodontically treated teeth. Dent Traumatol 2008 Apr;24(2):214-219.

8. Kishen A. Mechanisms and risk factors for fracture predilection in endodontically treated teeth. Endod Topics 2006 Mar;13(1):57-83.

9. Monga P, Sharma V, Kumar S. Comparison of fracture resistance of endodontically treated teeth using different coronal restorative materials: an in vitro study. J Conserv Dent 2009 Oct;12(4):154-159.

10. Ashika Riswana N, Kumari VA. Comparison of fracture resistance of endodontically treated tooth with composite and GIC as entrance filling - an in vitro study. J Pharm Sci Res 2015;7(11): 984-986.

11. Reddy SN, Harika K, Manjula S, Chandra P, Vengi L, Koka KM. Evaluation of occlusal fracture resistance of three different core materials using the Nayyar core technique. J Int Soc Prev Community Dent 2016 Jan-Feb;6(1):40-43.

12. Kane JJ, Burgess JO, Summitt JB. Fracture resistance of amalgam coronal-radicular restorations. J Prosthet Dent 1990 Jun;63(6):607-613.

13. Marshall GW Jr. Dentin: microstructure and characterization. Quintessence Int 1993 Sep;24(9):606-617.

14. Craig RG, Powers JM, Wataha JC. Properties of materials in dental materials. St Louis (MO): Mosby; 2004. p. 51-62.

15. Chutinan S, Platt JA, Cochran MA, Moore BK. Volumetric dimensional change of six direct core materials. Dent Mater 2004 May;20(4):345-351.

16. Asmussen E, Peutzfeldt A. Influence of UEDMA, BisGMA and TEGDMA on selected mechanical properties of experimental resin composites. Dent Mater 1998 Jan;14(1):51-56.

17. Helfer AR, Melnick S, Schilder H. Determination of the moisture content of vital and pulpless teeth. Oral Surg Oral Med Oral Pathol 1972 Oct;34(4):661-670. 